\title{
Making the Abstract Straightforward: A Pilot of Immersive VR in an Allied Health Program of Study
}

\section{Patrick Tod Colegrove ${ }^{1}$, Tammy Westergard ${ }^{2}$}

${ }^{1}$ University Libraries and Teaching \& Learning Technologies, University of Nevada, Reno, United States of America, ${ }^{2}$ Nevada State Library, Archives, and Public Records, United States of America.

\begin{abstract}
Emerging technologies in education are offering new tools for teaching and learner engagement. Today's study and practice can include use of digital technologies far beyond looking at a flat screen: virtual reality, augmented reality, interactive $3 D$ objects and 360 video can provide immersive and impactful teaching and learning. There are a variety of definitions for these "realities" but the overarching impact is one of powerful, immersive, visual learning. Immersive virtual reality in a learner-centric environment can provide more presence and engagement for students, enabling the possibility of enhanced learning experiences relative to conventional classroom practices. This paper presents formative early results of a pilot study leveraging the possibilities of VR technology in service to an existing program of study in allied health services:graduates surveyed report high degrees of confidence in course materials learned by means of the custom VR components developed, reporting the adjunct course materials substantially helped learners in understanding otherwise difficult to grasp concepts of the course.
\end{abstract}

Keywords: Virtual reality; educational technology; active learning; experiential learning; qualitative evaluation. 


\section{Introduction}

Emerging technologies in education are offering new tools for teaching and learner engagement. Today's study and practice can include use of digital technologies far beyond looking at a flat screen: virtual reality (VR), augmented reality (AR), interactive 3D objects and 360 video can provide immersive and impactful teaching and learning tools, (MartínGutiérrez, J., Mora, C. E., et al. (2017). There are a variety of definitions for these "realities" but the overarching impact is one of powerful, immersive, visual learning.

Libraries' use of virtual, augmented realities and 3D objects and video, like all technological advancements, has been growing and in flux for several years. However, in 2021, it is no longer seen as a technology whose time is yet to come - its rapid adoption in multiple areas of learning and workforce development is officially emergent in the area. Libraries of all types across the country are actively using VR/AR/3D technologies to drive accelerated learning, especially in STEM. According to a 2020 study in the British Journal of Educational Technology, students who use virtual reality in their science lessons across six weeks significantly outperformed the control group in terms of academic improvement (Bower, M., \& Jong, M., 2020).

Immersive virtual reality in a learner-centric environment can provide more presence and engagement for students, enabling the possibility of enhanced learning experiences as adjunct to conventional classroom practices (Kim, K., Oertel, C., et al. 2020). Leveraging the emergent classroom technology can create student engagement and enthusiasm (Chen, 2010); immersive virtual reality, compared to the conventional monitor-based low-immersion can enhance learning through situated experience with greater immersion, learning through multiple perspectives, and knowledge transfer through simulations of the real world (Dede, 2009). VR offers possibilities of creating immersive learning situations for the learners in a safe, exploratory practice space (Le, Q.T., Pedro, A., et al, 2015), encouraging students to be active learners and promoting decision-taking by enabling autonomous exploration and learning by doing, (Martin, Gutierrez, Mora, Anorbe-Diaz, et al, 2017)

This paper presents formative early results of a pilot study leveraging the possibilities of VR technology in service to an existing program of study in allied health services.

\section{Materials and Methods}

From 2019 - 2020 the Nevada State Library leveraged its partnership with the College of Southern Nevada and established subject matter experts in STEM skill development and career navigation to increase interest in Diagnostic Services Career Pathways and accelerate engagement with the Dialysis Laboratory Technician occupation. Purposeful, defined virtual reality tools and content workforce recovery training programs are advancing to support and 
influence workforce recovery in STEM fields that lead to living wage employment (Nevada Governor's Office of Economic Development, 2020); with immersive $360^{\circ}$ video, prospective students can literally see and experience if the Diagnostic Services Career Pathway is a good fit for their interest. Followed with a unique introduction to this pathway's occupations by means of VR content, and curated for diagnostic healthcare, the 3D content has the potential to cognitively anchor difficult science concepts while enabling the student to acquire a more meaningful understanding of "the job" (Dede, 2009).

In short, career exploration by means of a software-as-a-service database combining 360 video, STEM virtual reality, and data analysis modules, could create a "job coach on steroids". The authors piloted the development of the proof of concept program with the College of Southern Nevada dialysis technician program, and developed program assets that became homework help to students once enrolled in the program of study.

\subsection{State health need and occupation demand informed selection of the program of study}

Medicare, the federal health program in the United States for people 65 or older, in addition to certain individuals with disabilities, requires a national certification for any dialysis care technician employed within 18 months of hire date. This program is vital to the state's dialysis providers, as $21.1 \%$ of its population is dealing with kidney disease at various stages. The ability to meet growing regional demand for a highly skilled technical workforce is possible through this uniquely focused partnership. Constraints, or bottlenecks, to requisite in-person clinical hours were restricting the number of certified dialysis technicians in the talent pipeline. To manage the constraint, the proof of concept identified a clinical simulation option to drive unnecessary in person work study.

Dialysis patient care technicians work under the direction of nurses and physicians and perform dialysis on patients with acute or chronic kidney failure. These technicians operate dialysis machines that remove waste, salt, and extra water from the patient's blood while keeping safe levels of certain chemicals. Patient Care Technicians prepare patients for dialysis, monitor them, adjust settings on the machine, and perform required procedures upon completion.

\subsection{Demand for graduates greatly exceeded capacity of the program}

Medical and Laboratory Technician, identified by Nevada's Office of Science, Innovation, and Technology as a priority occupation in the Las Vegas Valley region, serves businesses that provide healthcare and social assistance to individuals. Employer identified skill gaps for qualified technicians include: processing information; interacting with computers to set up functions and enter data, and skill in observing, receiving and otherwise obtaining information from all relevant sources to make decisions; monitoring processes, materials or surroundings to detect or assess problems and evaluating information to determine 
compliance with standards. The Health Sciences Career Cluster prepares individuals for employment in the industry in general, and the Diagnostic Services Career Pathway specifically for the Medical and Laboratory Technician (aka Patient Career Technician) occupation (there are 16 total occupations in the Diagnostic Services Pathway). Total current employment in the Health Sciences Career Cluster is 53,928 and total projected employment by 2024 of 66,934, with a total annual demand for 2,465 (turnover + growth). Within the Diagnostic Services Career Pathway, including the Medical and Laboratory Technician occupation, total current employment is 4,640 and total projected employment in Nevada by 2024 of 5,869, with a total annual demand of 207 (turnover + growth).

The existing College of Southern Nevada's (CSN) Dialysis Patient Care Technician (PCT) certificate of completion, as well as the nationally recognized Certified Clinical Hemodialysis Technician (CCHT) credential, is recognized and valued by companies employing Patient Career Technicians in Southern Nevada; however, employers needed to see it expanded to grow the pipeline of skilled workers available to dialysis providers and other advanced technology healthcare sectors.

\subsection{Developing the VR course adjunct materials need and occupation demand}

Once the program of study had been selected for the pilot, the implementation group met with the instructor of record in the context of the classroom for an in-depth discussion and exploration of which point or topics of the course of study students could most benefit from access to customized VR learning content. In particular, the core question posed was to ask the instructor to think back to their most recent cohort of students in the program: was there one concept, topic, or lecture that was most central or key in the long-term success of students in the program? That is, a concept or skill that once mastered, the instructors' confidence that the student would successfully complete the training and be gainfully employed.

The lead instructor of the program walked to the classroom whiteboard, and began sketching the outlines and describing the fundamental nature of the dialysis procedure. Illustrated with a photograph in Figure 1, the "extra-corporeal circuit" mapped out how the patient's blood flows through the tubing - taped to the whiteboard for effect - through the various pieces of the equipment, to the "dialyzer" that effectively filters the blood, ultimately returning to the patient's arm. The instructor explained that without a core understanding of each of the aspects illustrated, in conjunction with basic STEM skills and mathematical ability, students would ultimately prove incabable of completing the course and acquiring the certification needed to practice. It was a complicated lesson, and one the instructor explained typically took an entire class period, and clearing up misunderstandings throughout the remainder of the course.

Virtual reality STEM publisher, Lifeliqe, LLC, Lifeliqe was contracted to create an immersive VR learning module to address the learning need and enable students to self-teach 
by means of the immersive adjunct VR content. Titled simply "Dialysis," the application provided an option to explore 12 interactive 3D models, wherein the user can explore different parts of the 3D models, with each part having additional information about itself, in depth. Made available as a "channel" unlocked with a license key made available to all libraries within the proof of concept area and the College of Southern Nevada (CSN), students enrolled in the program could leverage the simulation at their local public library branch.

The course instructor further identified specific topics from the curriculum used in the Dialysis Patient Care Technician core curriculum that benefit from practice. Each practice module was designed to be self-paced and provide instant feedback on learner responses. Students could visualize reactions and processes while solving problems in real-time. Importantly, the modules combine real world context in a virtual dialysis center, requiring learners to think critically and perform mathematics in their development of specific quantitative reasoning. In a virtual environment designed to enable students to learn "hands on," students can return to the modules at any time for practice. Learning supplements have indefinite shelf lives, as the science behind the curriculum is longstanding.

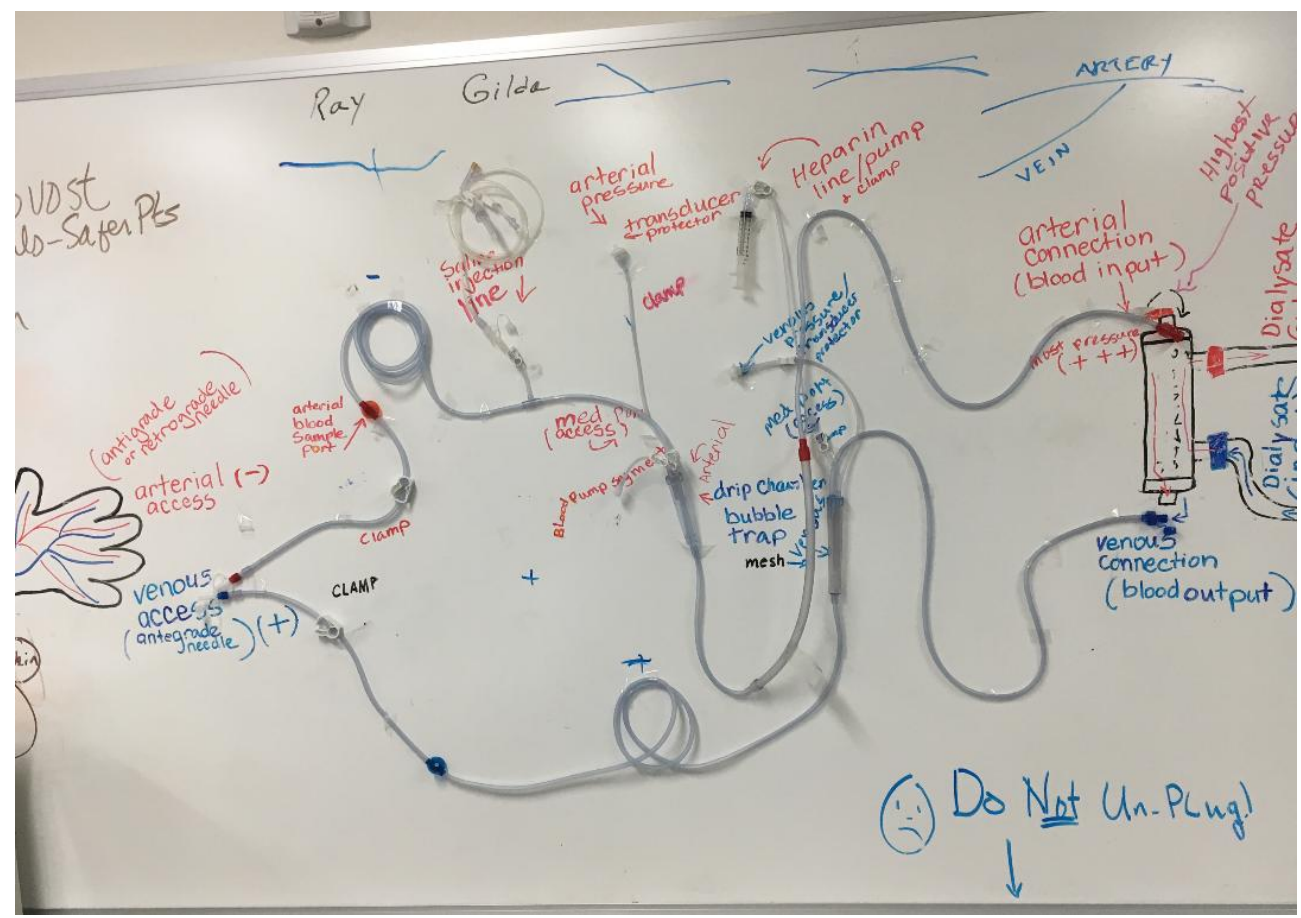

Figure 1. The extra-corporeal circuit, as taught to the traditional classroom by means of a whiteboard, annotations, and discussion. 


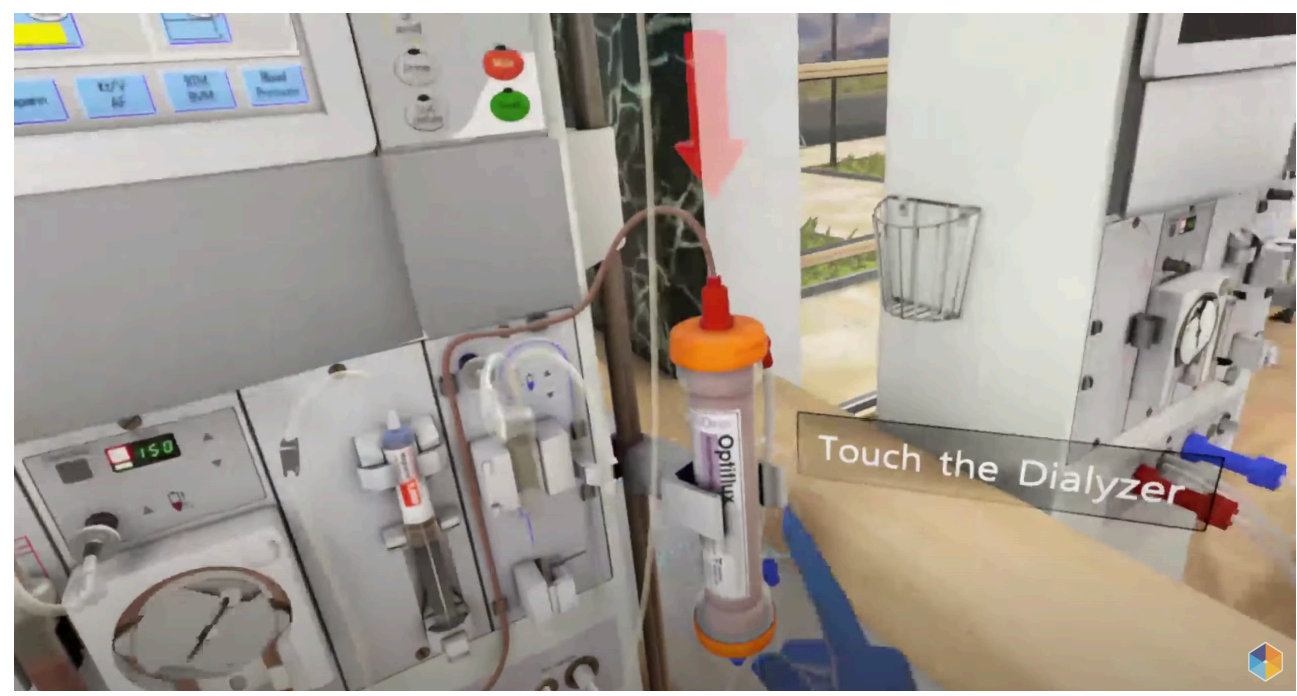

Figure 2. Rather than a theoretical discussion in front of a whiteboard, the VR simulation places the learner directly in the context of the dialysis workplace. Note the embedded learning cues such as "touch the dialyzer" offering immediate feedback.

\section{Results}

Although insights are formative and not validated externally, early results from a pilot study interrupted by the onset of the novel COVID-19 pandemic, based on the impact the of the immersive VR content and its utility the decision was made to transition the program to an online format supplemented by the VR content made available through the public library. Rather than cancelling courses currently underway, despite the pandemic and associated restrictions, of the 12 students enrolled in the program 11 were able to successfully complete the program. The ultimate indicator of success, each of the graduates gained immediate employment in the discipline at competitive rates of pay - in spite of an economic environment brought on by pandemic closures resulting in unemployment for well over $30 \%$ of the regional population.

Although the conditions of the pilot had shifted, with the VR component shifting from homehork help to becoming actual laboratory and coursework, feedback was gathered from students in the cohort upon completion is useful for others that may be contemplating similar work. Responses to the anonymized in-depth survey offer insight into the degree to which the VR component improved learning outcomes, including on respondent stating the primary benefit of "being able to visualize the concepts". That statement was echoed by another stating the VR component "helped me much in understanding the concepts." Yet another compared the immersive three-dimensional VR content to a two-dimensional video on a flat 
screen, pointing out that the "new and different environment and was very helpfully [sic] and much better than traditional learning materials to exhibit the practical ablity of the process".

When asked whether the addition of 3D interactive and virtual reality content to the program increased their confidence going into the midterm exam, all respondents seemed to echo the statement one student made, simply "I am confident about using what I have learned." The majority responded at the highest affirmative level, with the remainder indicating only one step down from the highest level of confidence. Indeed, the impact on confidence had one student reporting "I opened the models when we were waiting to enter the classroom to take our midterms and I passed on first try."

Notably, some students reported experiencing dizziness, or a sense of claustrophobia when wearing the VR headset and chose instead to use simulation on their cellphone or tablet computer. Access to the content overall seemed transformative to the students' learning experience, with one student summing the experience up simply: “...my first day was like whoa this is an actual water room. It gives you an idea on what you can expect."

\section{Discussion and Directions of Future Work}

Although this paper reports promising findings from the initial pilot study of implementing customized VR experiences as adjunct training facilities in an allied healthcare program of study, they are formative at best and should be validated by other study. There is a need for a more structured longitudinal study to document potential impact and begin steps toward eliciting best practices. Nevertheless, from a practical standpoint this pilot has already demonstrated that coursework formerly restricted to the classroom and clinical workplace can be expanded with judicious selection, development, and implementation of VR adjunct course material. A case in point, the program at the College of Southern Nevada has not only been able to maintain a pipeline of course graduates to serve the growing need, but to expand the number - even as the quality of the learning may be increased by the access to the immersive learning environment. Further, the development and access to the VR content enabled a successful transition to a fully online program, lifting former geographical limitations on enrollment and potentially expanding the program well beyond the local area.

There is a need for additional build out of supporting modules in the existing course of study, even as it is underway with additional cohorts. Even among the first cohort there was a call from the students to include additional content, such as a variety of emergency situations that might arise. As one of the respondents noted, "It seems to only be a smidgen of what is actually done in the clinic and even in the classroom. I don't know how costly or how much work it would take... but it would be awesome to see more." It would be good to include actual fiscal impact in future work, speaking both to the costs of development and 
implementation, as well as the potentially increased impact and cost-benefit of both learners and the educational institutions involved.

Based on the strength of these initial results, in addition to building out additional models in support of the current certification program of dialysis technicians, there is a clear opportunity to leverage such customized VR content to increase efficacy of instruction in similarly difficult to learn topics. The framework and methods described in this paper could be relatively easily applied to meet needs in similar programs of study across higher education. In particular, the potential to open up and expand access for individuals unable to learn effectively by means of traditional classroom methods, particularly in STEM disciplines, promises to not only transform individuals' lives, but to impact local economies in a positive way.

\section{Acknowledgements}

This project was made possible in part by the Institute of Museum and Library Services through the Library Services and Technology Act.

\section{References}

Bower, M., \& Jong, M. (2020). Immersive virtual reality in education. British Journal of Educational Technology, 51(6), 1981-1990.

Chen, M. (2010). Education nation: Six leading edges of innovation in our schools. Hoboken, NJ: Wiley \& Sons, Inc.

Dede, C. (2009). Immersive Interfaces for Engagement and Learning. Science Magazine, 323(5910), 66-69. https:// DOI: 10.1126/science.1167311

Kim, K., Oertel, C., et al. (2020). Using immersive virtual reality to support designing skills in vocational education. British Journal of Educational Technology, 51(6), 2199-2213.

Le, Q.T., Pedro, A., et al. (2015). A Social Virtual Reality Based Construction Safety Education System for Experiential Learning. Journal of Intelligent \& Robotic Systems, 79, 487-506.

Martín-Gutiérrez, J., Mora, C. E., Añorbe-Díaz, B., et al. (2017). Virtual Technologies Trends in Education. Eurasia Journal of Mathematics, Science and Technology Education, 13(2), 469-486. https://doi.org/10.12973/eurasia.2017.00626a

Nevada Governor's Office of Economic Development. (2020). Annual Report. Carson City, NV: Nevada Governor's Office of Economic Development. Retrieved from https://goed.nv.gov/wp-content/uploads/2021/02/GOEDAnnualReport20Proof3new.pdf 